\title{
Study on the Blended Modification of Polystryrene and Low Density
}

\section{Polyethylene}

\author{
Jun Zhou ${ }^{1, a^{*}}$, Chun-Ling Shi ${ }^{1, b}$, Wei Yue ${ }^{1, c}$ \\ ${ }^{1}$ School of Chemical Engineering and Technology, Xuzhou Institute of Technology, Xuzhou, Jiangsu, \\ China
}

aemail: zhoujunxz@126.com, bemail: 529876358@qq.com, cemail: 644810298@qq.com

Keywords: Low density polyethylene; polystyrene; blended modification; mechanical property Abstract: In this paper, the main work is to use one of the five general synthetic resin of low density polyethylene (LDPE) on the blending modification of polystyrene (PS) to overcome the faults such as brittle, environmental stress cracking resistance, low impact strength of PS and improve their mechanical properties, then enlarge its application scope. Through tensile mechanical and impact performance tests of the blended mixture of LDPE/PS with different proportions, we can find the performance of the blends is the best and the tensile strength reached the maximum, while the elongation at break and impact strength are also high with $91.7 \%$ and $84.6 \%$, respectively. Their performance reached the level of practical application and has certain practical value so could be expected to be carried out for industrial production.

\section{Introduction}

As one of the five common thermoplastic synthetic resin of polystyrene (PS) with good rigidity, good transparency and relatively easy to dye, good electrical insulation performance, processing good formability, and the price is cheaper, etc. It has a wide range of applications on the instrument, construction, packaging, household appliances, electronics, daily necessities and toys and other industries. But the nature of the PS, brittle, thermal deformation temperature is relatively low, only $70 \sim 98{ }^{\circ} \mathrm{C}$, environmental stress cracking resistant, the impact strength is not high also. So the application of PS has been limited ${ }^{[1-2]}$. The performance of LDPE is contrary to PS with high impact strength, good toughness, and low temperature, but its rigidity is poor ${ }^{[3]}$. According to blend theory, we expect to improve the their performance through blending LDPE with PS and eventually get a new material excellent performances of two kinds of resin and can make up for their shortcomings.

The composite material is a new material, which is formed by two or more than two kinds of material or artificial synthesis. The two main types of materials can be classified into functional composite materials and structural composite materials. Composite materials commonly used have a variety of fiber, metal wire and inorganic rigid particles, etc. Blending modification can improve the physical and mechanical properties, transparency, coloring, antistatic property, and can reduce the production cost ${ }^{[4]}$.

In this paper, LDPE was modified to improve the mechanical properties of PS. We tried to get a best blended proportion of LDPE and PS through investigation on the impact strength, the tensile strength and the elongation at break of the LDPE/PS composite materials with different ratios. 


\section{Experimental section}

$1 \mathrm{Kg}$ of blended materials of LDPE/PS were accurately weighed and the ratio of mass fraction of LDPE is $0 \%, 20 \%, 40 \%, 60 \%, 80 \%$ and $100 \%$, respectively. Table 1 lists the material used in the experiment and their specifications. The blended particles were processed in the injection molding machine and five of impact and tensile splines of each group which meet the standard of GT/T 1043.1-2008 were prepared. Tensile and impact tests were carried out with the electronic universal mechanical testing machine and impact test machine with a simply supported beam.

Table 1 Materials and their specifications

\begin{tabular}{cc}
\hline Materials & Specifications \\
\hline PS & QG7535 \\
LDPE & SH3060 \\
\hline
\end{tabular}

\section{Results and discussion}

Through the blending modification experiment, we found that the different proportion of LDPE has great influence on the mechanical properties of the blends. Table 2 exhibits the total data of the effect of content of LDPE on the mechanical properties of LDPE/PS composites materials.

Table 2 The total data of the effect of LDPE content on the mechanical properties

\begin{tabular}{ccccccc}
\hline Content $(\%)$ & 0 & 20 & 40 & 60 & 80 & 100 \\
\hline Impact strength $\left(\mathrm{au} \mathrm{kJ} / \mathrm{m}^{2}\right)$ & 8.13 & 6.88 & 5.63 & 2.87 & 6.88 & 80.94 \\
Tensile strength $(\mathrm{MPa})$ & 15.58 & 11.25 & 12.78 & 13.38 & 16.28 & 12.31 \\
Elongation at break $(\%)$ & 40.9 & 33.9 & 44.0 & 7.3 & 37.5 & 563.3 \\
\hline
\end{tabular}

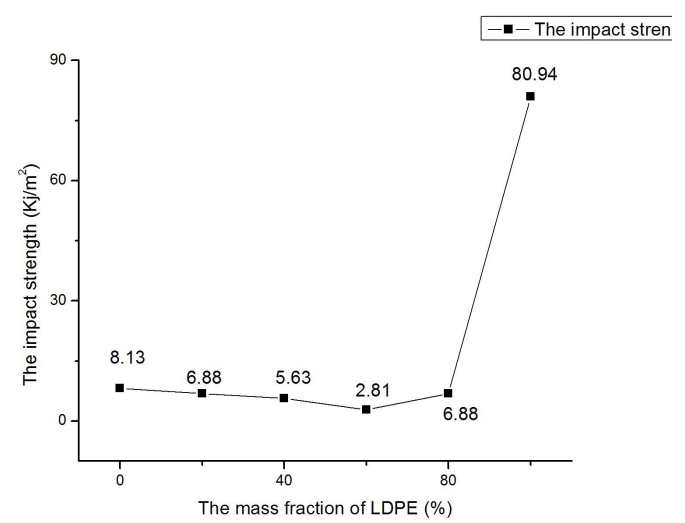

Figure 1 Effect of the content of LDPE on the notched impact strength of LDPE/PS composites

Seeing from figure 1, when the content of LDPE was $80 \%$ and $20 \%$, the notched impact strength of LDPE/PS was $6.88 \mathrm{KJ} / \mathrm{m}^{2}$ and is the maximum. But the notched impact strength of the blends was still decreased by $15.4 \%$ than that of PS. When the content of LDPE was $60 \%$, the notched impact strength of of the blends was the minimum and decreased to $2.81 \mathrm{KJ} / \mathrm{m}^{2}$ and was decreased by $65.4 \%$ than that of PS. It can be seen that the impact strength of the blends decreased after adding LDPE into PS and the blending effect is not very ideal. 


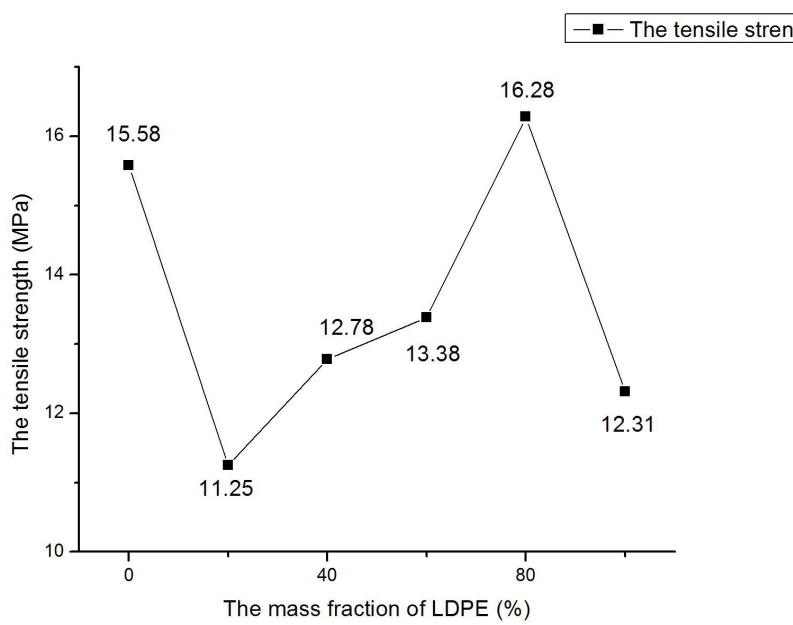

Figure 2 Effect of the content of LDPE on the tensile strength of LDPE/PS composites

Seeing from figure 2, when the content of LDPE was $80 \%$, the tensile strength of the blend was the maximum, and high to $16.28 \mathrm{Mpa}$. The tensile strength was increased by $4.5 \%$ than that of PS and $32.3 \%$ than that of LDPE. When the content of LDPE was $20 \%$, the tensile strength of the blend was the minimum and decreased to $11.25 \mathrm{Mpa}$. The tensile strength was decreased by $27.8 \%$ than that of PS and $8.6 \%$ than that of LDPE.

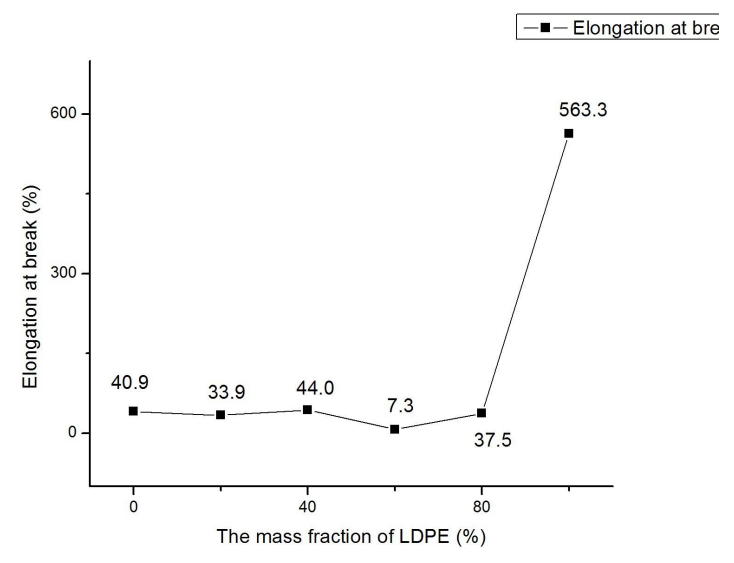

Figure 3 Effect of the content of LDPE on the elongation at break of LDPE/PS composites

We can see from figure 3 that when the content of LDPE was $40 \%$, the elongation at break of the blends was the maximum and reached to 44 . The elongation at break of the blends was increased by $7.6 \%$ than that of PS. When the content of LDPE was $60 \%$, the elongation at break of the blends was the minimum and decreased to 7.3. The elongation at break of the blends was decreased by $82.2 \%$ than that of PS.

\section{Conclusions}

Through analysis of the data of the tensile test and impact mechanics experiment of LDPE/SBS, we found the impact strength of the blends have not been improved but declined, while the tensile strength and elongation at break it were improved. In general, when the content of LDPE is $80 \%$, the comprehensive properties of the blends the best. 


\section{Acknowledgements}

The authors are grateful for financial support from General Program on University Science Research of Jiangsu Province (Grant No. 15KJB480003) and Research Project of Xuzhou Institute of Technology (Grant No. XKY2014311).

\section{References}

[1] Eidelman S, Hayes K G, Olive K A, et al. Review of particle physics[J]. Physics Letters B, 2004, 592(1): 1-5.

[2] Haijun Yao, Yongqing Yang, Xinlin Chang, ect. Research progress on modification methods of polystyrene and its application[J]. Chemical Engineering and Equipment, 2009, (7): 142-145. (In Chinese)

[3] Wenbing Xie, Wei Wang. Study on the mechanical and rheological properties of polystyrene/polyethylene blends[J]. Petrochemical Technology, 1998, 27(3): 176-182. (In Chinese)

[4] Aixin Yang, Shenyan Cui. Hubei chemical industry, 2000, 17(1): 31-32. (In Chinese) 